\title{
Feasibility of Pulverized Oyster Shell as a Cementing Material
}

\author{
Chou-Fu Liang and Hung-Yu Wang \\ Department of Civil Engineering, National Pingtung University of Science and Technology, 1 Hsuefu Road, Neipu, \\ Pingtung 91201, Taiwan \\ Correspondence should be addressed to Hung-Yu Wang; hywang@mail.npust.edu.tw
}

Received 9 November 2012; Revised 27 February 2013; Accepted 4 March 2013

Academic Editor: Alex Li

Copyright ( $\odot 2013$ C.-F. Liang and H.-Y. Wang. This is an open access article distributed under the Creative Commons Attribution License, which permits unrestricted use, distribution, and reproduction in any medium, provided the original work is properly cited.

\begin{abstract}
This research intends to study the cementing potential of pulverized oyster shell, rich in calcium, when mixed with fly ash and soil. Cylindrical compacted soil and cubic lime specimens with different proportions of the shells and fly ash are made to study the strength variance. Soil, which is classified as CL in the USCS system, commercialized pulverized oyster shell, F-type fly ash, and lime are mixed in different weight percentages. Five sample groups are made to study the compressive strength of soil and lime specimens, respectively. The lime cubes are made with $0.45 \mathrm{~W} / \mathrm{B}$ ratio and the cylindrical soils are compacted under the standard Procter compaction process with $20 \%$ moisture content. The results show that increment of shell quantity result to lower strength on both the soil and lime specimens. In a 56-day curing, the compressive strength of the lime cubes containing fly ash increases evidently while those carrying the shell get little progress in strength. The soil specimens containing fly ash gradually gain strength as curing proceeds. It suggests that mixtures of the shell and fly ash do not process any Pozzolanic reaction nor help to raise the unconfined strength of the compacted soil through the curing.
\end{abstract}

\section{Introduction}

Being an island, Taiwan is very rich in marine resources. Along the west coast of Taiwan, oyster farming is one of the most important production activities for the country's economy. In general, most of the oyster shells are discarded with no further use once the flesh is stripped off; except that a small amount is used for art creation $[1,2]$. As a result, oyster shell piles are common in areas of oyster production with no further utilization. Chemical and microstructure analyses reveal that oyster shells are predominantly composed of $\mathrm{CaO}[3,4]$, similar to that of lime, which has been used for soil stabilization [5]. In addition, oyster shells can be utilized for producing medium- and high-quality cement [6]. The expandable nature of clay is reduced by the ion exchange from the interaction between calcium ions and clay. Quicklime creates coagulation if added with water. Thus, calcium ions are used generally as the primary component in the clay stabilization. There is no known chemical reaction between soil and lime except the ion exchange. In other studies for potential use, the shells are mostly used as additive or replacement of part of the cement in concrete.
For example, construction material mixed with crushed oyster shell and sand was used for sand compaction piles to improve soft soils underneath a breakwater port in Japan [7]. However, the lime contained in the shells does not provide improvement of concrete strength as the Pozzolanic products of concrete already contain lime, and therefore no positive effect is detected for concrete strength. According to [8], a pozzolan is defined as a siliceous and aluminous material, which in itself possesses little or no cementitious value but will, in finely divided form in the presence of moisture, chemically react with calcium hydroxide to form compounds possessing cementitious properties (Pozzolanic activity).

No concrete strength increase was found by adding sintered and pulverized oyster shells to concrete [9]. As a result, the use of pulverized oyster shells as concrete additive or cement replacement often needs to be combined with other bonding materials, such as fly ash or slag [8]. Only the Pozzolanic reaction between $\mathrm{SiO}_{2}$ in the fly ash or slag and $\mathrm{CaO}$ in the pulverized oyster shells, along with the addition of water reducer or superplasticizer, can improve the strength of pulverized-oyster-shell-added concrete. 
TABLE 1: Weight proportion of ingredients in cubic specimens.

\begin{tabular}{lccc}
\hline Group & Lime & Fly ash & POS* $^{*}$ \\
\hline A & 40 & 40 & 20 \\
B & 40 & 20 & 40 \\
C & 40 & 30 & 30 \\
D & 100 & - & - \\
E & - & 50 & 50 \\
\hline
\end{tabular}

* Pulverized oyster shell.

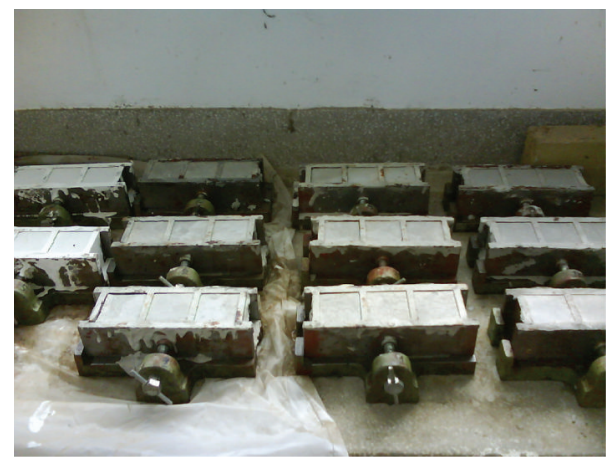

Figure 1: Cubic specimens in the study.

Considering the scale of construction industries in the near future it is imperative to guarantee a secure supply of high-quality sand resources. Therefore, it is essential to conduct a research for other alternatives to meet future demands. Our research involves two major parts: first, the Pozzolanic reaction between F-type fly ash and the pulverized oyster shelland secondly, the improvement of soil strength, if the combination of pulverized oyster shells, clay, and sand can effectively improve the physical properties of soil such as strength $[5,6]$. However, most of soil stabilization is done by in situ mixing, paving, and compacting. It is unlikely to obtain good control as it does in concrete mixing.

\section{Specimens in the Tests}

Lime cube specimens (125 cubic $\mathrm{cm}$ each) as illustrated by Figure 1 were made for testing the Pozzolanic potential of fly ash and oyster shell. There are five groups of cubic specimens with different proportions of lime, fly ash, and pulverized oyster shell. Each group contains 3 specimens. According to [10], using the water/cement ratio of 0.5 , the comprehensive strength can reach 3000 psi (minimum comprehensive strength required for primary structures) for the replacement of percentage of oyster shell when it is $30 \%$. To reach the same comprehensive strength for the water/cement ratio of 0.6 , the replacement of oyster shell powder should be lower than $20 \%$. For all mix designs, when the replacement percentage of oyster shell powder is $40 \%$, the comprehensive strengths for them are all lower than 3000 psi. These render such concrete suitable for secondary structures. Hence, we choose W/B 0.45 and 40\% weight of lime in the mixture of specimens. The lime is originally proposed to provide the adhesion for fixing the cubes, due to its low

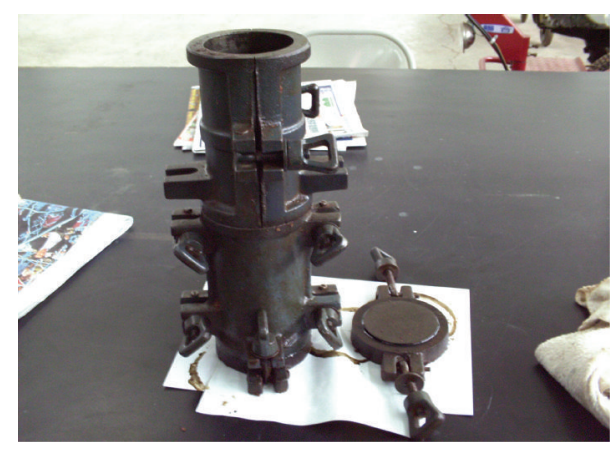

FIGURE 2: Soil compaction mould assembly modified from concrete specimen mould.

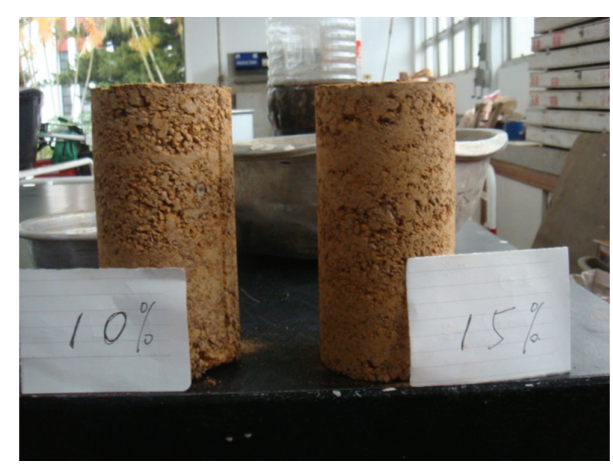

FIgURE 3: Compacted soil specimens.

strength after hardening, in case that the Pozzolanic reaction between fly ash and the oyster shell does not occur. However, the lime, when mixed with fly ash, becomes a main character providing the compressive strength of the cubes at the end of the study. The ratios of the ingredients, shown in Table 1, are chosen since the study mainly focuses on the reaction between fly ash and the shell, not the optimum ratio of the ingredients.

A USCS-classified CL soil is used in the compaction. The analysis of basic physical soil properties in the laboratory revealed that the plastic limit was $11 \%$ and liquid limit $25 \%$, resulting in the plasticity index of $14 \%$, which classifies the soil used to be low-plasticity soil according to the unified soil classification. The soil contained approximately $90 \%$ of fine particles, as the size of most particles was smaller than $2.75 \mathrm{~mm}$ (i.e., number 4 sieve). Only $2 \%$ of the particles were greater than $2.75 \mathrm{~mm}$ in size. The specific weight of soil particles was 2.63 .

The Proctor (ASTM D698-12) standard compaction test was selected for soil dynamic analysis. Cylindrical soil specimens of $7.5 \phi \times 15 \mathrm{~cm}$ were prepared for unconfined compression test in order to find out the influence of pulverized oyster shells to the compression strength of soil. If the soil specimens were taken from the compacted soil in a standard compaction mould using thin tube, the sampling would create excessive disturbance affecting the test result. Considering the minimization of disturbance to soil specimens, the standard compact mould was not used for compaction in the specimen 
TABLE 2: Weight percentage of ingredients used in soil specimens.

\begin{tabular}{lccc}
\hline Group & Soil & Fly ash & POS* $^{*}$ \\
\hline A & 100 & - & - \\
B & 95 & - & 5 \\
C & 85 & - & 15 \\
D & 95 & 5 & - \\
E & 85 & 7.5 & 7.5 \\
\hline
\end{tabular}

${ }^{*}$ Pulverized oyster shell.

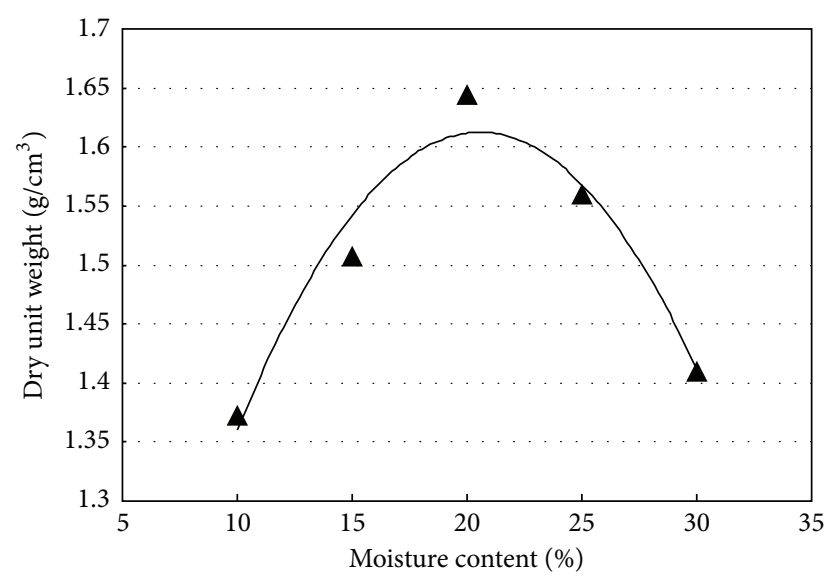

FIgURE 4: Compaction curve of soil group A.

preparation. Instead, a steel concrete specimen mould of $7.5 \phi \times 15 \mathrm{~cm}$ was chosen for compaction. Two steel moulds were connected with screws (Figure 2) to allow complete filling of soil in the mould. The number of hammering was calculated based on the compaction energy received per soil volume in the standard compaction test.

Specimens were produced with repeated compactions and $1.2 \mathrm{~kg}$ of soil was used to fill the mould in three layers. Eight compactions were exercised for every layer. Specimens were produced at a height of roughly $16 \mathrm{~cm}$ based on the soil weight and procedure. The part of soil hanging outside of the mould was carefully removed using a steel saw, thus resulting in cylindrical specimens of $7.5 \phi \times 15 \mathrm{~cm}$ (Figure 3 ) and eliminating the disturbance that sampling with thin tube would have caused, in the hope of minimizing test error.

Specimens were separated in 5 groups, in each of which different proportions in weight of pulverized oyster shells and fly ash were added in place of partial soil for specimen production. The purpose was to investigate the influence of pulverized oyster shells and fly ash to the compression strength of soil. The composition of each group is shown in Table 2. The compression test was carried out on days $7,28,60$, and 90 to investigate the changes of unconfined compression strength at different days.

\section{Water in the Compacted Soil}

The maximum dry density of soil sample and the difficulty of removing the specimens from mould must be considered, as the specimens produced for the study were not made in

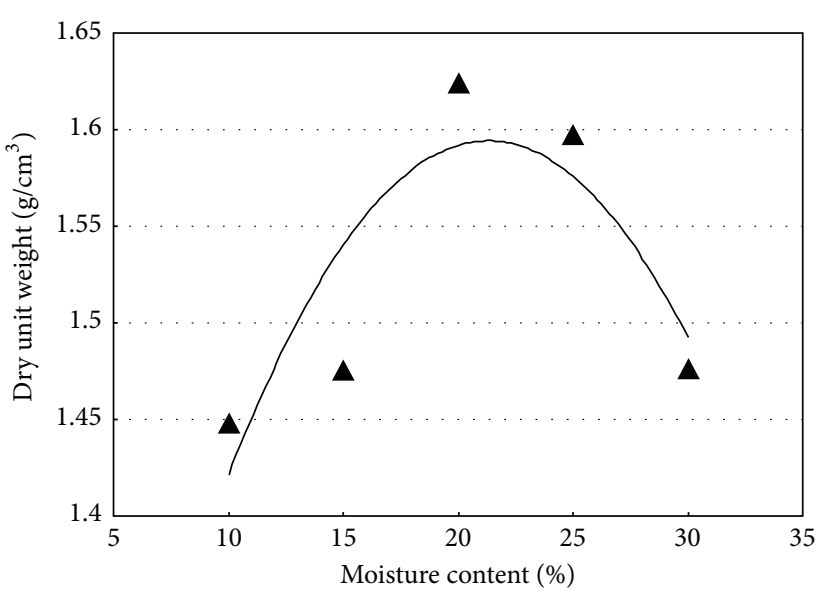

Figure 5: Compaction curve of soil group B.

the standard mould. The soil of each group was compacted according to the compaction energy and soil weight determined previously. The compaction result of some of the soil is shown in Figures 4, 5, and 6.

From the above, it is found that the addition of pulverized oyster shells improved the optimal moisture content in the soil from $20 \%$ to nearly $25 \%$. Therefore, the soil was less sensitive to water, allowing the increase of moisture in soil without making the soil too soft. As nonstandard procedure was adopted for the compaction test, it is necessary to consider how to keep the specimens intact when removing them from moulds, and the soil strength, as well as the test result, is susceptible to moisture content. By considering both factors above and conducting trial and error, it is realized that the easiest way is to remove the specimens from the moulds at the content of $20 \%$. As a result, the moisture content of $20 \%$ was used for the compaction of specimens. The changes in the strength of each group of specimens at the maximum dry density are not covered in this study.

The wet specific weight of specimens obtained in the compaction test was calculated based on 30 specimens taken from each group and is shown in Table 3, which indicates that the homogeneity of the specimens produced was satisfying with the specific weight of all specimens at $2.04 \mathrm{~g} / \mathrm{cm}^{3}$ for maximum (Group A) and $1.87 \mathrm{~g} / \mathrm{cm}^{3}$ for minimum (group E). The error of the maximum and minimum specific weights of the soil specimens relative to the average specific weight felt between $2.27 \% \sim 2.64 \%$ with the largest difference of $4.16 \%$ occurring in Group E. At a specific weight of 2.2, the addition of pulverized oyster shells decreased the specific weight of soil specimens, suggesting that the specific weight of soil specimens decreases with the increase of addition of pulverized oyster shells, dropping from $1.97 \mathrm{~g} / \mathrm{cm}^{3}$ for pure soil to $1.94 \mathrm{~g} / \mathrm{cm}^{3}$ with the difference in specific weight at only $1.8 \%$.

\section{Specimen Curing and Compression Test}

To prevent water in the specimens from vaporizing, the specimens were wrapped in plastic film when produced 
TABLE 3: Specific weights of soil specimens by group.

\begin{tabular}{|c|c|c|c|c|c|}
\hline \multirow{2}{*}{ Project } & \multicolumn{5}{|c|}{ Group } \\
\hline & A & B & $\mathrm{C}$ & $\mathrm{D}$ & $\mathrm{E}$ \\
\hline Average & 1.97 & 1.97 & 1.94 & 1.97 & 1.95 \\
\hline Standard deviation & 0.03 & 0.02 & 0.02 & 0.02 & 0.03 \\
\hline Maximum (homogeneous difference \%) & $2.04(3.73)$ & $2.02(2.47)$ & $1.99(2.60)$ & $2.01(1.75)$ & $2.01(2.64)$ \\
\hline Minimum (homogeneous difference \%) & $1.91(3.24)$ & $1.92(2.43)$ & $1.89(2.27)$ & $1.92(2.64)$ & $1.87(4.16)$ \\
\hline
\end{tabular}

TABLE 4: Compressive strength of lime cubes.

\begin{tabular}{|c|c|c|c|c|c|}
\hline \multirow{2}{*}{ Time (day) } & \multicolumn{5}{|c|}{ Compressive strength $\left(\mathrm{N} / \mathrm{cm}^{2}\right)$} \\
\hline & $\mathrm{A}$ & B & $\mathrm{C}$ & $\mathrm{D}$ & E \\
\hline \multirow{3}{*}{7} & 48.3 & 26.1 & 32.5 & 33.7 & 28.4 \\
\hline & 54.5 & 23.9 & 33.0 & 33.0 & 25.8 \\
\hline & 43.1 & 25.5 & 32.1 & 40.3 & - \\
\hline \multirow[t]{2}{*}{ Average } & 48.6 & 25.2 & 32.5 & 35.7 & 27.1 \\
\hline & 192.5 & 29.7 & 63.2 & 46.0 & 34.2 \\
\hline \multirow[t]{2}{*}{8} & 159.5 & 28.1 & 83.4 & 47.2 & 33.0 \\
\hline & 221.8 & 17.1 & - & 40.6 & - \\
\hline \multirow[t]{2}{*}{ Average } & 191.3 & 24.9 & 73.3 & 44.6 & 33.6 \\
\hline & 324.2 & 32.8 & - & - & 39.3 \\
\hline \multirow[t]{2}{*}{56} & 402.0 & 44.3 & 122.1 & 37.8 & 35.8 \\
\hline & 436.5 & 42.0 & 179.2 & 27.4 & - \\
\hline Average & 387.6 & 39.7 & 150.7 & 32.6 & 37.6 \\
\hline
\end{tabular}

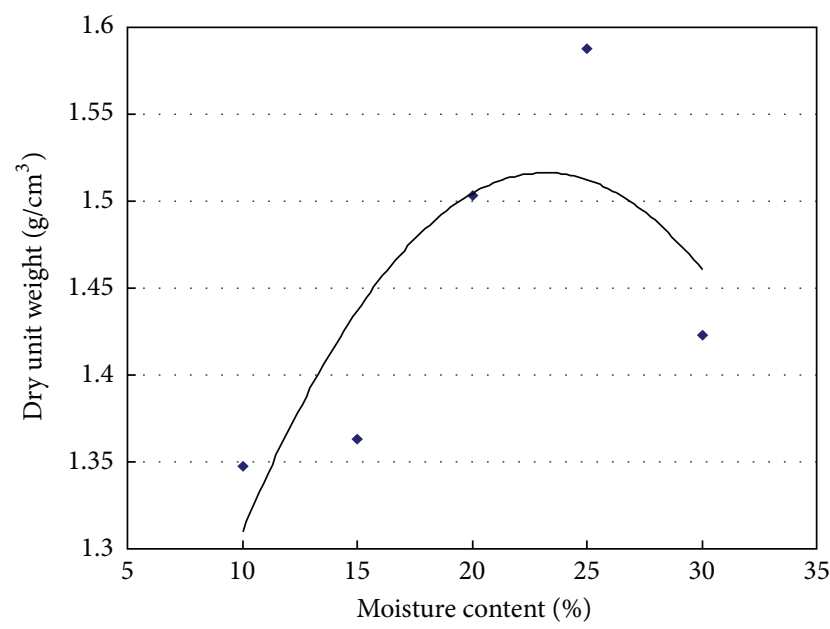

FIgURE 6: Compaction curve of soil group C.

(Figure 7) and placed in large plastic bags. Small amount of water was sprinkled in the plastic bags every week to keep the specimens properly moist, keeping in mind not to allow excessive moisture in them to ruin the result of compression test to come.

The unconfined compression test (i.e., the uniaxial compression strength test) was carried out at days 7,28 , and 75 of specimen curing to investigate the long-term influence of pulverized oyster shells and fly ash to the compression strength of compacted soil. The moisture content was measured after the

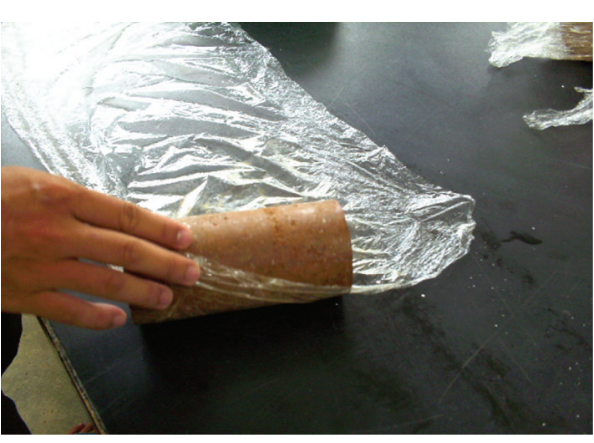

FIGURE 7: Compacted soil specimens wrapped for curing.

compression test to determine the effect of the curing method on the moisture maintenance in soil.

\section{Test Result}

The lime cubes were then tested on the 7th, 28th, and 56th day. The results are shown in Table 4 and Figures 8 and 9. It shows that Pozzolanic reaction between fly ash and POS does not occur as expected. The strength of cube A gets higher as the curing time elapses, while cube $\mathrm{E}$ only gets slight increase in strength. It is reasonable to conclude that the strength of cube A is mainly gained from the Pozzolanic products from lime and fly ash. In addition, the compressive strength of the cubes is smaller as the weight percentage of pulverized oyster shell increases (Figure 9). The compressive strength of the D and $\mathrm{E}$ cubes eventually becomes the same 


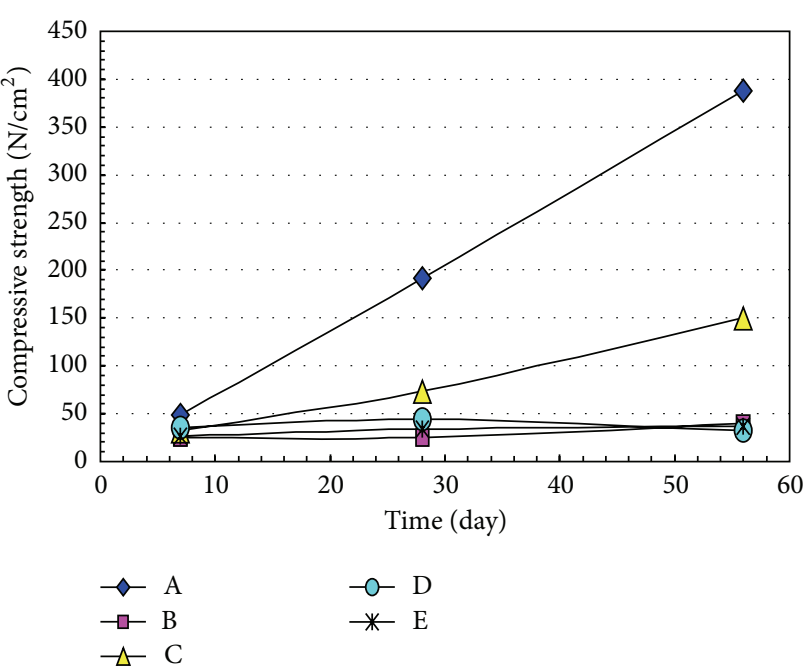

Figure 8: Strength development of lime cubes.

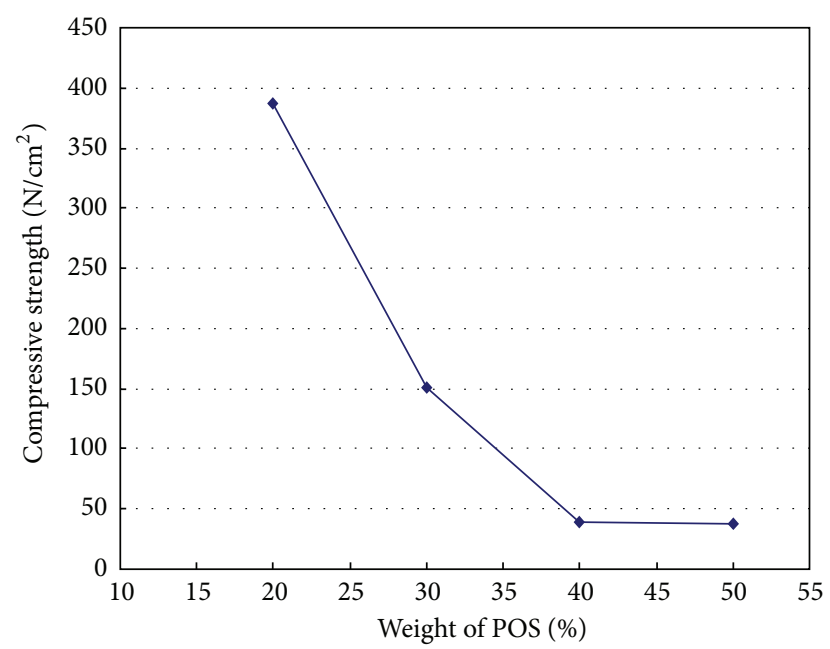

FIGURE 9: Strength of lime cubes versus weight percentage of pulverized oyster shell.

at any curing age. It suggests that, for the time being, the commercialized pulverized oyster will not have too much help in the Pozzolanic reaction with fly ash.

The compressive strength test on compacted soil specimens was scheduled at days 7, 28, 60, and 90. However due to equipment servicing, it was rescheduled at days 7,28 , and 75 of specimen age. Table 5 shows the strength of each group of specimens versus curing time, whereas Figure 6 gives the maxima of compression strength at each of the days.

From Tables 4 and 5 and Figure 10 above, it is clear that the addition of pulverized oyster shells gave no significant improvement for the compacted red soil taken from the National Pingtung University of Science and Technology campus in terms of the unconfined compression strength. The comparison of Groups A, B, C, and E in Figure 10 shows that the strength decreased significantly with the increasing addition. It is possible that no ion exchange occurred between the pulverized oyster shells chosen for this study and the

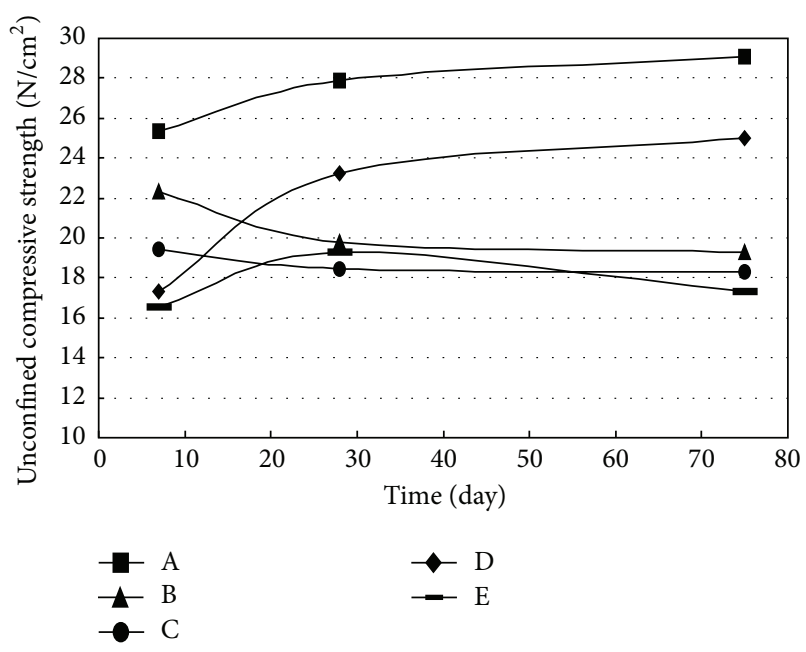

Figure 10: Unconfined strength of compacted soil.

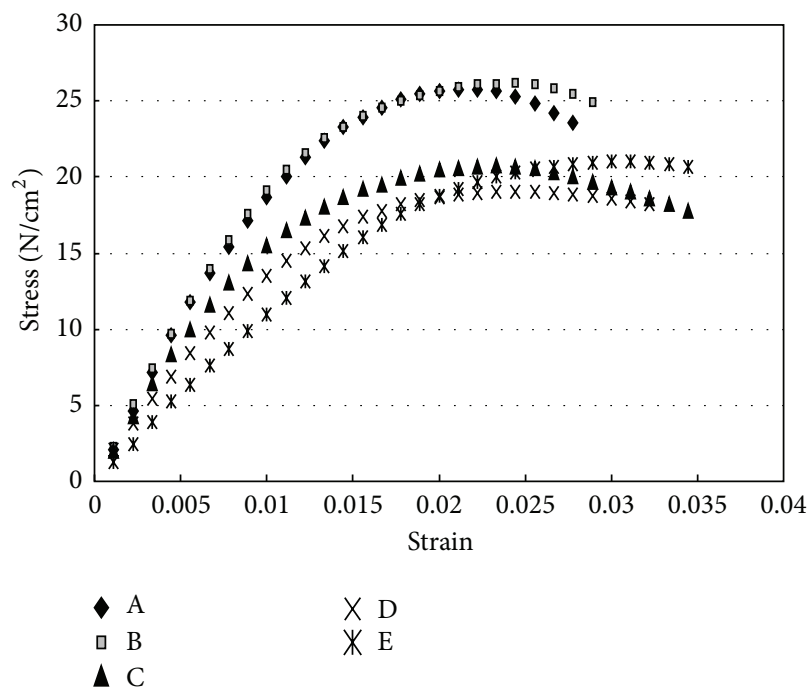

Figure 11: Stress and strain of the compacted soil at 7 days.

clay, or the soil samples taken for this study might not be expansive, leading to no obvious iron exchange.

The addition of fly ash also led to decrease in the compression strength of the soil used in the study. However, its compression strength displayed a gradual increase. The addition of both pulverized oyster shells and fly ash in the soil did not provide the improvement in soil strength as the addition of only pulverized oyster shells did. It is concluded that the addition of both pulverized oyster shells and fly ash in Group E specimens did not improve the compression strength of soil by inducing the Pozzolanic reaction as expected.

Figures 11 and 12 show the stress-strain curves for each group of specimens at days 7, 28, and 75 in the compression strength test. The result suggests that the stress-strain curves become less steep with the decrease of strength. In addition, the compacted soil becomes soft and susceptible to displacement with the increasing addition of pulverized oyster shells. 
TABLE 5: Unconfined compression strength of soil specimens for groups with different ages.

\begin{tabular}{|c|c|c|c|c|c|}
\hline \multirow{2}{*}{ Time (day) } & \multicolumn{5}{|c|}{ Compressive strength $\left(\mathrm{N} / \mathrm{cm}^{2}\right)$} \\
\hline & A & $\mathrm{B}$ & $\mathrm{C}$ & $\mathrm{D}$ & $\mathrm{E}$ \\
\hline \multirow{3}{*}{7 days } & 22.1 & 23.5 & 20.7 & 15.6 & 21 \\
\hline & 25.7 & 26.2 & 17.4 & 17.4 & 16.5 \\
\hline & 28.2 & 17.2 & 20.2 & 19 & 12.2 \\
\hline Average & 25.3 & 22.3 & 19.4 & 17.3 & 16.6 \\
\hline \multirow{3}{*}{28 days } & 27.5 & 21 & 15.9 & 23.5 & 20.9 \\
\hline & 29 & 17 & 17.5 & 22.8 & 19.4 \\
\hline & 27.2 & 21.4 & 21.9 & 23.5 & 17.5 \\
\hline Average & 27.9 & 19.8 & 18.4 & 23.3 & 19.3 \\
\hline \multirow{3}{*}{75 days } & 28.1 & 19.6 & 16.8 & 21.6 & 17.5 \\
\hline & 27.3 & 18.1 & 18.5 & 27.5 & 16.1 \\
\hline & 31.9 & 20.1 & 19.6 & 25.9 & 18.4 \\
\hline Average & 29.1 & 17.3 & 18.3 & 25 & 17.3 \\
\hline
\end{tabular}

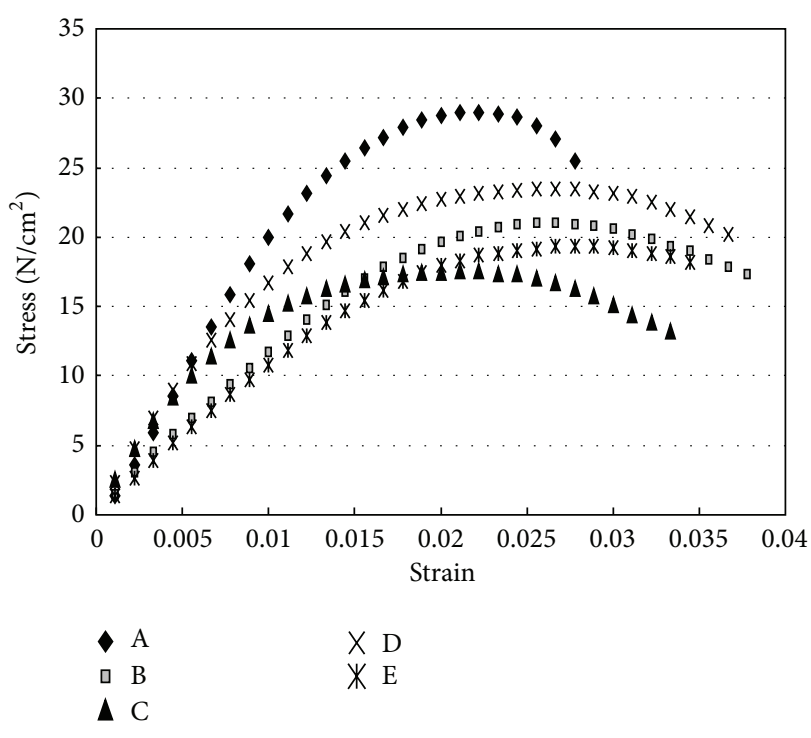

FIGURE 12: Stress and strain of the compacted soil at 28 days.

\section{Conclusion and Suggestions}

Standard moulds were not used for the compaction. However, the test result shows that the compaction is reasonable, and the specific weight of compacted soil suggests consistency of soil result. Therefore, the compaction selected for this study is feasible. The addition of pulverized oyster shells improves the optimal moisture content in the soil; that is, it decreases the sensitivity of soil to moisture content. However, at a specific weight of 2.2, the pulverized oyster shells do not improve the maximum dry density of the soil when added. The marketavailable pulverized oyster shells used in the study do not improve the compression strength of compacted soil in the experiment, and the drop of compression strength grows increasingly clear with the increase of addition. The test result suggests neither significant Pozzolanic reaction between the pulverized oyster shells used and the fly ash nor improvement of soil strength by adding both pulverized oyster shells and fly ash. The application of lime is a common and viable practice in soil stabilization and Pozzolanic reaction with fly ash. However, the strength improvement in compacted soil and lime blocks using lime-rich pulverized oyster shells perhaps is limited to the fineness and activity of pulverization, soil type, and aggregates. The same conditions do not apply to all test configurations. It is probably feasible to use pulverized oyster shells for their lime-rich nature in soil stabilization or in reaction with fly ash. However, the study did not yield the expected compressive strength increase in both compacted soil and lime blocks. How to improve the practicality of using pulverized oyster shells in soil stabilization remains to be investigated. The soil used in this study does not expand, resulting in lack of expected outcome. A test conducted on expandable clay may be considered to determine the suitability of pulverized oyster shells.

\section{References}

[1] “Fisheries Statistical Yearbook 1993-2001," Fisheries Agency, Council of Agriculture, Executive Yuan, Republic of China, http://www.fa.gov.tw/.

[2] "Study on the processing of waste oyster shells, National Taiwan Ocean University, Fisheries Bureau, Department of Agriculture and Forestry, Province of Taiwan," pp. 126-128, 1997.

[3] T. C. Chu, Influence of replacement of cement and fine aggregates with waste pulverized oyster shells to the properties of cement mortar [M.S. thesis], Graduate Institute of Construction Engineering, National Yunlin University of Science and Technology.

[4] G. L. Yoon, B. T. Kim, B. O. Kim, and S. H. Han, "Chemicalmechanical characteristics of crushed oyster-shell," Waste Management, vol. 23, no. 9, pp. 825-834, 2003.

[5] M. G. Spangler and R. L. Handy, Soil Engineering, Harper \& Row, 4th edition, 1982.

[6] B. Y. Zhong, Q. Zhou, C. F. Chan Y, and Y. Yu, "Structure and property characterization of oyster shell cementing material," Chinese Journal of Structural Chemistry, vol. 31, no. 1, pp. 85-92, 2012.

[7] Y. Miyaji and T. Okamura, "Geo-material properties of wasted oyster shell sand mixture and its application as material for sand 
compaction pile," in Proceedings of the Coastal Geotechnical Engineering in Practice, pp. 675-680, Rotterdam, The Netherlands, 2000.

[8] V. G. Papadakis and S. Tsimas, "Supplementary cementing materials in concrete: part I. Efficiency and design," Cement and Concrete Research, vol. 32, no. 10, pp. 1525-1532, 2002.

[9] T. H. Wu, Study on the stabilization of various roadbed soils using pulverized oyster shells [M.S. thesis], National Cheng Kung University, Taiwan, 2000.

[10] C. J. Lee, A study on the application of oyster powder as a cementitious material [M.S. thesis], National Taiwan Ocean University, Taiwan, 2005. 

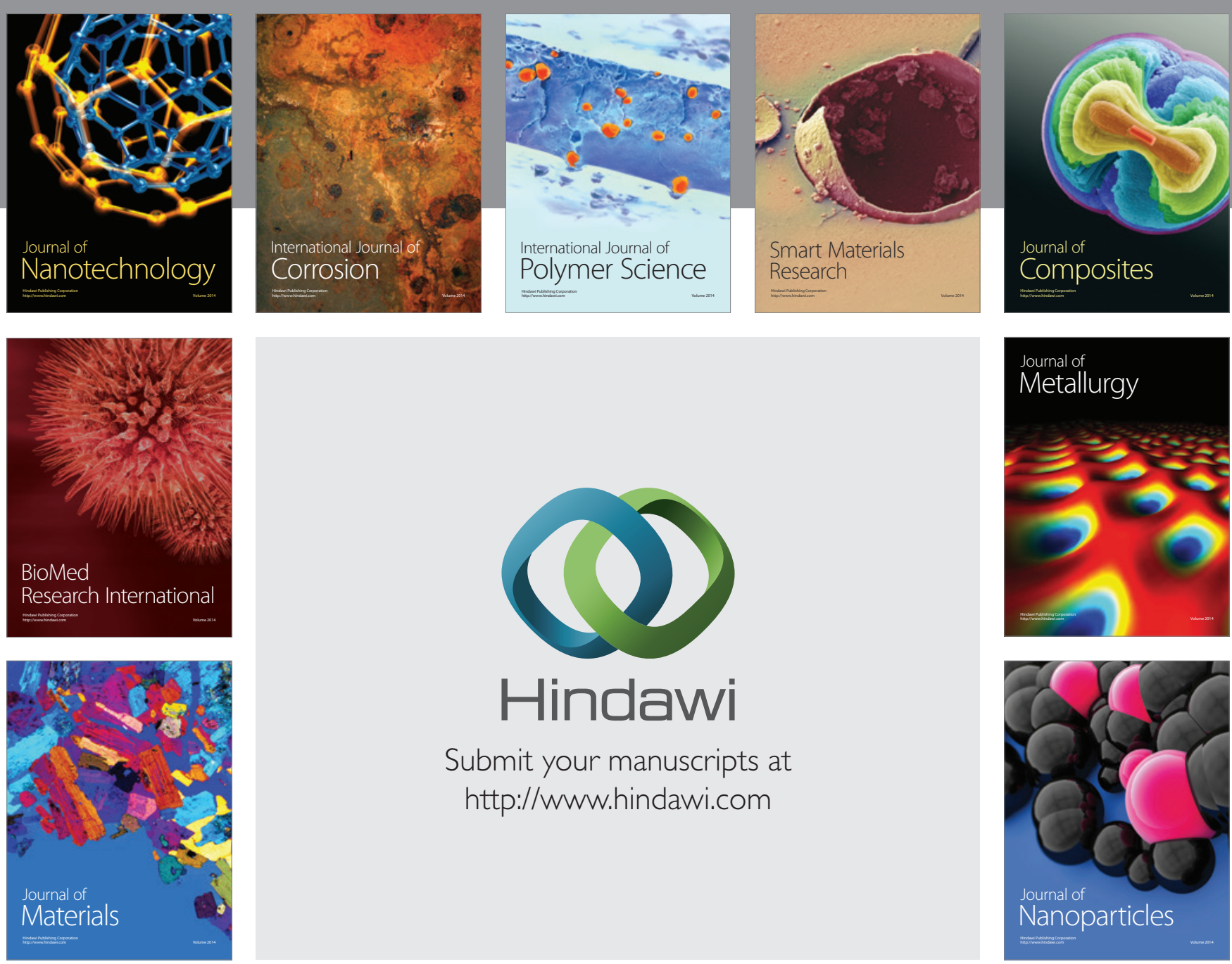

Submit your manuscripts at http://www.hindawi.com
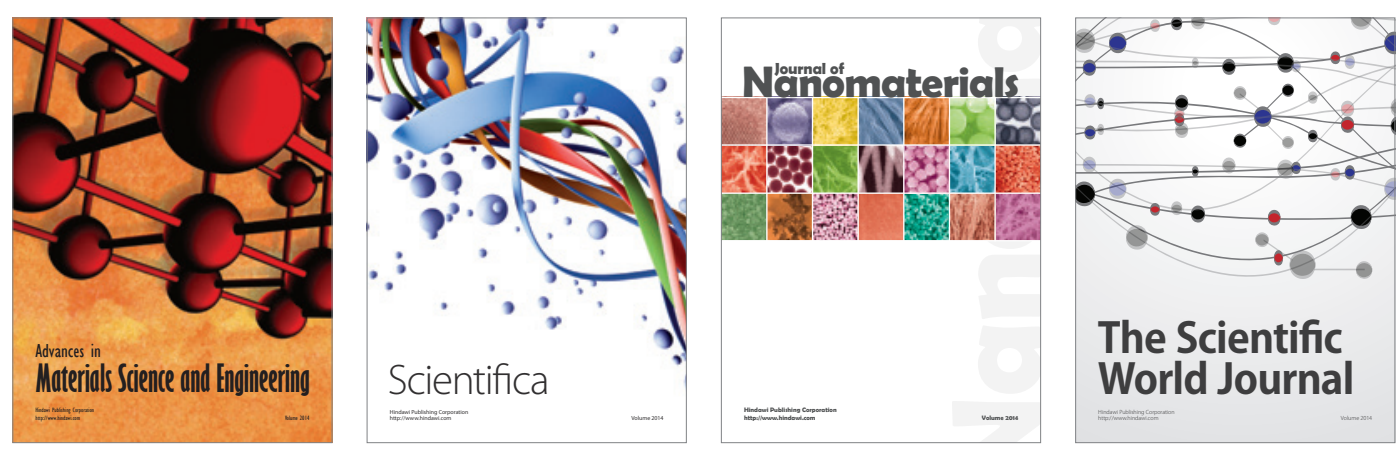

\section{The Scientific World Journal}
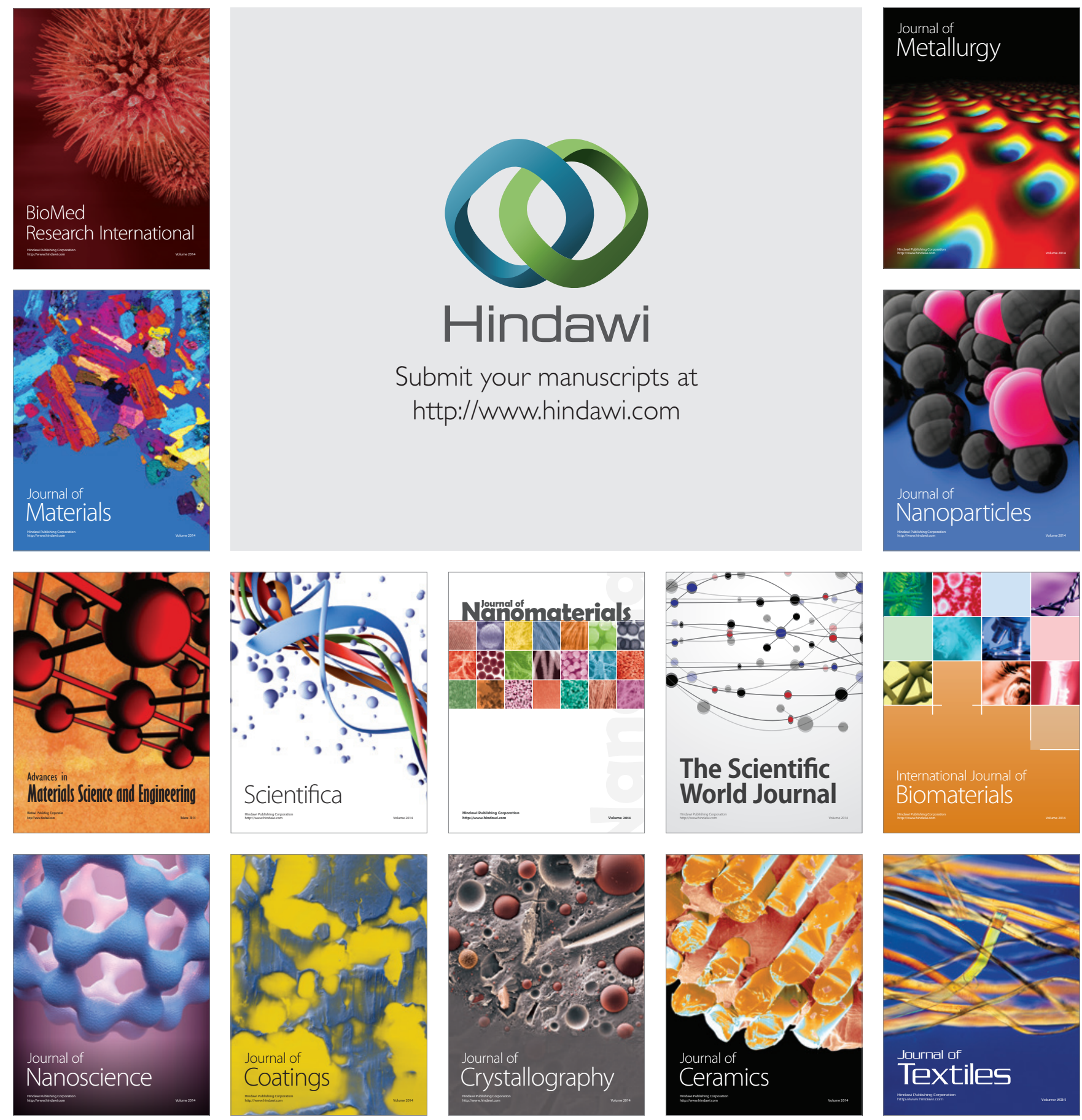